making this year's competition a success.

Michael T. Adams, Northern Illinois University, "Abortion Politics and Public Health Policy: The Case of Abortifacient RU486"

Catherine A. Claxton, Cornell University, "RU486: Strategies in the Politics of Abortion"

Kim Kissinger, Northern Illinois University, "Intellectual Property Rights in Biotechnology: Will Third World Dependency Increase?"

Regina Olshan, Dartmouth College, "Good Samaritan Law - An Ethological Perspective”

Timothy J. Ressmeyer, Northern Illinois University, "Regulation Policy and Consumer Protection for Users of In Vitro Fertilization"

\section{REPORT TO APLS COUNCIL}

\section{MEMORANDUM}

TO: $\quad$ APLS Council

FROM: Ad Hoc APLS Membership Committee

DATE: $\quad$ May 24,1990

RE: Committee Report

\section{APLS Membership: A Committee Report}

An Ad Hoc Membership Committee was set up after the 1989 annual Council meeting in Atlanta. Serving on the Committee were Andrea Bonnicksen (chair), William Brandon, Roger Masters, and Albert Somit. Three members of the Committee (Brandon, Somit, and Bonnicksen) met in Chicago on December 16-17, 1989. The same three met for a second time and were joined by Odelia Funke while attending the MWPSA in Chicago on April 6, 1990. They also met with Tom Wiegele and other APLS members (Bob Blank, Richard Hartigan, Claude Phillips) attending the MWPSA on April 6. Other business was conducted by telephone and mail and included the sugges- tions and responses of Roger Masters. The Committee wishes to thank Odelia Funke for setting up the Committee; Tom Wiegele for sending material, allocating money for the Committee's work, and offering encouragement; Bill Brandon for his statistical analysis and report of membership patterns; and Bob Blank, Ira Carmen, Richard Hartigan, and Claude Phillips for their suggestions.

The Committee's goals were to (1) discuss the nature of the membership issue, (2) review steps already taken to increase membership, (3) suggest ways of gathering information about membership patterns, and (4) develop a list of ideas to be discussed by the APLS Council at its annual meeting in 1990. The following summarizes the Committee's discussions. The Committee members are aware of the difficulty of undertaking new recruitment strategies. Later in the report we address the problem of who might undertake these responsibilities. The report includes two appendices: Appendix I ("An Analysis of APLS Membership Retention," compiled and written by Bill Brandon) and Appendix II ("Summary of Survey Results of Members Who Dropped, 1988-89").

\section{Nature of the Issue}

The Committee concludes that APLS is a healthy organization with a strong core membership (see Appendix I). Membership has declined since 1987, but this was the year the Lilly Foundation grant expired and less money was available for continued aggressive recruiting. The membership is higher than it was during the Association's first three years. This is a potential growth period, and new markets, including the international market, remain largely untapped. The percentage of international members has remained stable over time: $17 \%$ (1985), $17 \%$ (1986), $15 \%$ (1987), 15\% (1988), 15\% (1989). The recent participation of the managing editor of Politics and the Life Sciences $(P L S)$ in a meeting about marketing journals overseas is a positive sign that the Association is committed to tapping this market. Several specific suggestions were included in the report, "International Marketing Plan for Politics and the Life Sciences."

The Association has maintained an active core of members while keeping membership costs low. The effort to keep down membership fees is to be commended. Even if the membership or fees are doubled, the journal will still not be self-sustaining. The Committee believes that the membership issue is not serious enough to warrant a significant increase in membership fees. The issue is twopronged: recruiting new members and retaining existing 
members. The ideas suggested below are stated with the presumption that a major increase in membership fees is not forthcoming.

\section{Gathering Information}

To deal with the problem of retaining existing members, the Committee conducted a telephone survey of U.S. based members who dropped APLS membership between 1988 and 1989. Of the list of 50,17 agreed to a short telephone interview. Some respondents answered only some of the questions. A summary of the responses is attached in Appendix II. Several general conclusions can be drawn:

- Members were drawn to APLS membership by the promise of the subject matter.

- The multidisciplinary appeal of APLS is evident by the range of expectations of members about the subject matter. It is also evident by the list of other organizations to which the former members belong.

- More people dropped their membership for nonsubstantive reasons (retirement, forgot about it) than for reasons dealing with the subject matter.

- Members read PLS articles and book reviews and they found the format appropriate and the content interesting.

- Those who had opinions about possible changes in the journal tended to favor more articles. They also suggested the need for less technical articles.

- The members who dropped would not have been influenced by additional APLS services, such as a newsletter or conferences.

These findings are limited by the fact that they are based on a small sample of members who dropped. This is the first time former members have been contacted, however. The findings suggest that APLS is reaching diverse audiences. They also suggest that the journal can appeal to those broad audiences more effectively by including varied articles covering more topics and articles written in a form that can be understood by those interested in biopolitics but who are not specialists in its subfields.

To continue to gather information about members' needs, the Committee suggests that all new members receive a thank you letter for joining and a short set of questions designed to find out their reasons for joining and expectations about benefits of membership. This can be in the form of a written survey to be returned to the APLS office. The responses can be kept on file for use in strategies about retaining new members.

\section{Strategies for Recruitment}

The Committee believes that an important part of recruiting and retaining members is to create a feeling of benefit of being an APLS member. The positive feeling of being a "member" of the Association can be heightened by costeffective methods such as the following:

- A personal letter to each new member thanking him or her for joining

- A statement by the APLS Council President in each issue of PLS

- A newsletter published between issues of PLS serving as a clearinghouse for information about grants, jobs, and members' activities. The first (welcome and interesting) issue of this newsletter has been published, with Steven Peterson and James Schubert serving as editors.

- A conference held independently and in alternate years (perhaps on another continent) of the APSA annual meeting, possibly oriented around a specific issue or topic. The conference might be held (1) at a different time and place from the APSA, (2) the day before the APSA meeting, or (3) in conjunction with the conference of another association (e.g., Political Psychology). A step in this direction (and a model to look at) has been undertaken by Steven Peterson and James Schubert in the Workshop on Empirical Research in Biopolitics they organized at Alfred University in 1990.

- Application by members to the National Endowment for the Humanities to conduct a Research Seminar, Summer Seminar, or Summer Institute with APLS co-sponsorship. This will publicize the Association and encourage members to participate in the Seminar or Institute. Roger Masters has suggested a Summer Faculty Seminar cosponsored by another organization such as the Gruter Institute as a way of reaching political scientists interested in biopolitics.

- Holding an annual round-table panel at regional political science meetings such as the MWPSA or SPSA. Concern was expressed that holding regular APLS panels (papers and discussants) at each regional meeting might detract from participation at the APSA-APLS panels. Hence, a round-table format designed to attract those with a tan- 
gential interest in biopolitics might be an alternative such as a round-table entitled "Animal Rights: A Multidisciplinary Perspective."

- The commitment by individual members to recruit new members on a one-to-one basis through personal contacts. Over the long-run this might be the most effective recruiting strategy possible. The Committee suggested that members go one step further than merely recommending membership to colleagues and also act as a "mentor" to at least one new member and encourage that person to present papers at or attend APLS panels and to submit articles to PLS. An apparent " 3 year itch" is described in Appendix I in which nonrenewal rates are higher at the end of two years of membership. In light of this finding, the Committee recommends "targeting" members during their second year for instance by personally inviting them to participate in an APSA/APLS panel. The idea of a mentor might be particularly useful at this point.

- Individual members are encouraged to "sell" biopolitics as an established area in political science in order to create an established niche of biopolitics. The stronger the biopolitics niche, the more the "trickle-down" effect of encouraging political scientists to join APLS, as an organization dealing with the life sciences. This can be done by such things as becoming members of editorial boards of journals and trying to secure a biopolitics section in the APSA credential service newsletter.

- Continue efforts to tap other constituencies in developing panels at the APSA (e.g., the panel on surrogate motherhood at the 1989 meeting was developed with the Women's Caucus of APSA).

- Consider compiling an edited book along the lines of "The Best of APLS" containing the top articles published in PLS's first decade.

- Send relevant articles from PLS to the "In the Literature" section of the Hastings Center Report for summaries in that section.

- If financially possible, set up a booth displaying NIU Press and APLS literature at regional political science meetings.

The APLS office has targeted many audiences for mail solicitations for membership (a list of the organizations that have given membership lists to APLS is available from Tom Wiegele). The Committee members have brought together additional suggestions that may or may not have already been tried:
- Secure the mailing list of the Canadian Public Health Association and continue efforts to reach the public health community.

- Obtain the International Directory of Bioethics Organizations from the Kennedy Institute of Ethics at Georgetown University to learn the institutional subscribership of each. Send a letter to the directors of the libraries of each to increase library subscribership to PLS.

- To tap the audience in bioethics, make two changes in the recruitment brochure the next time it is published. Under "The Association" add the word "ethical" to state: "Almost as quickly as it has been produced, it has had theoretical and public policy influence-raising serious political, philosophical, legal, ethical, and social questions." Also under "The Association" change "political science" to "the behavioral sciences" to read: "Representing a serious and continuing commitment to a life science orientation within the behavioral sciences, the Association ..."

- Make one change in the letter sent to librarians. In the first sentence add "ethics" and "behavioral" to state: "Is an interdisciplinary journal of vital interest to those in the biological and behavioral sciences; political science; biomedical ethics; and science, technology, and society programs."

- Continue with present efforts to contact persons who are members of the APSA subsection but are not APLS members.

- Continue with present efforts to contact members of related APSA subsections.

- Go through Dissertation Abstracts and the lists of Ph.D.'s recently completed in PS to identify new Ph.D.'s interested in politics and the life sciences. Send special letters congratulating them on completing their degrees and inviting them to join. This is an effort to tap the newest market and maintain long-term membership among its scholars.

- Continue with efforts to recruit members internationally. This can be done through direct mailings and through publicity at other international conferences (e.g., the IPSA conference to be held in Argentina in 1991). Mailings can be sent to international political science groups such as the German PSA, French PSA, and Australasian Political Studies Association. Particular attention should be given to European APLS members, and conferences should be held occasionally in Europe to accommodate those members and to entice American members interested in traveling abroad. 


\section{For Discussion at 1990 Council Meeting}

Council members have received under separate cover a letter from Roger Masters containing ideas for discussion about (1) a cooperative agreement between APLS and another group such as the Evolution and Human Behavior Society or the Gruter Institute for Law and Behavioral Research, and (2) a cooperative merger between PLS and another journal such as the Journal of Social and Biological Structures. The Ad Hoc Membership Committee agrees that these are important options to be discussed in the effort to secure the financial future of the journal.

The Committee weighed the possibility of organizational innovations in APLS as a way enacting these and other methods of recruiting and retaining members. We recommend that the Council consider setting up a study committee on organizational innovations. Among the questions to be discussed by the committee are the following:

1. Is it appropriate to re-examine the APLS Constitution to see if it is consistent with the evolving APLS organization?

2. Is a more decentralized model of administration appropriate in which responsibility is delegated to members in different regions or states?

3. As a way of delegating authority (and work) is it desirable to distinguish between the editorship of the journal and the Executive Directorship of the Association?

4. Are there specific ways of revitalizing the Council so that it will take on an increased role in everyday Association duties?

5. How might a greater portion of APLS membership be involved in APLS duties and decisions?

The examination of the APLS organization is based on the assumption that the more members who are involved in recruitment and retention activities, the greater the likelihood they will feel a part of the organization and will retain their own membership. In addition, greater decentralization, with more responsibility placed on individual members, might be effective in reaching prospective members at the "grass-roots" level. It might be desirable, for example, to appoint regional APLS representatives to be responsible for organizing a round-table and leaving APLS brochures at regional political science meetings. It might be appropriate to appoint an APLS member to be respon- sible for identifying and writing to new Ph.D.'s who specialize in biopolitics. Such decentralization of responsibility would take additional coordination by the Council and the Association office, but it would have the advantages of involving more members, dividing the workload, and distributing the costs of APLS mailings.

\section{Appendix I \\ An Analysis of APLS Membership Retention}

William P. Brandon

Seton Hall University

The Ad Hoc Membership Committee of the Association for Politics and the Life Sciences (APLS) was established in Autumn 1989 to study the issues raised by a reported $37 \%$ decline in personal membership of the organization from 1988 to 1989. After increasing for four years, a slight decrease in membership had been registered in the middle of the previous year (Table 1). The organization's leadership defined the problem largely in terms of a failure of members to renew (Table 2). A significant decrease in personal membership threatens the vitality of the organization, even if library and institutional membership continues at the present level or grows.

The Ad Hoc Membership Committee focused principally on retention of existing members instead of studying the characteristics of the total membership or the new members whom APLS attracts each year. This appendix explores the issue of membership retention using data derived from membership lists from 1 July 1985 through January 1990 and the tables developed in the middle of each calendar year by APLS Executive Director Thomas C. Wiegele.

An important conclusion of this appendix is that retention rates were essentially the same in 1989 and four years earlier, when APLS was growing steadily and there was no perception of a retention crisis. Slightly more than threequarters of its members residing in the U.S. renewed in both 1986 and 1989; members residing outside the U.S. have renewed at similar or even slightly higher rates in recent years.

Membership loss was less last year than during 1988. Thus, the organization may be returning to positive growth. If the annual year-end membership lists are accurate, the actual decline in personal membership was 28 members between the end of 1987 and the end of 1988 and 21 members between the end of 1988 and the end of 1989 (Table 3). 
Table 1

APLS Membership by Category
FY 1983 - FY 1989

\begin{tabular}{lcrrrrrr}
\hline Category & $6 / 30 / 83$ & $6 / 30 / 84$ & $6 / 30 / 85$ & $6 / 30 / 86$ & $6 / 30 / 87^{*}$ & $6 / 30 / 88$ & $6 / 30 / 89$ \\
\hline $\begin{array}{l}\text { Personal } \\
\quad \text { Student }\end{array}$ & 113 & 132 & 196 & 211 & 262 & 241 & 151 \\
$\quad$ Individual & 17 & 18 & 41 & 24 & 26 & 18 & 15 \\
$\quad$ Sustaining & 70 & 86 & 145 & 174 & 224 & 212 & 124 \\
Library & 26 & 28 & 10 & 13 & 12 & 11 & 12 \\
Institutional & 40 & 51 & 78 & 123 & 140 & 140 & 135 \\
Total & 3 & 3 & 3 & 3 & 3 & 3 & 3 \\
\hline
\end{tabular}

Source:Thomas C. Wiegele, APLS Executive Director.

*End of three-year promotion effort funded by the Lilly Endowment.

Table 2

Membership Renewal

Selected Years and Categories

(In percent)

\begin{tabular}{lccc}
\hline Category & $\begin{array}{c}1988 \\
\text { (Renewing in 1989) }\end{array}$ & $\begin{array}{c}1985 \\
\text { (Renewing in 1986) }\end{array}$ & $\begin{array}{c}1987 \\
\text { (Renewing in 1988) }\end{array}$ \\
\hline Personal & $76.8^{\star}$ & $77.4^{\star}$ & \\
$\quad$ Student & 83.3 & & \\
$\quad$ Individual & 58.5 & & \\
Sustaining & 100.0 & \\
Library & 96.4 & $77^{\star}$ \\
Non-U.S. Residents & $87^{\star}$ &
\end{tabular}

Source:Thomas C. Wiegele, APLS Executive Director, and the annual membership lists.

*Calculated by the author using membership lists dated January 1, 1986-1990. Other figures were provided by Dr. Wiegele and probably represent mid-year data, which may help to explain discrepencies. 
The perception of a crisis was based on mid-year reports that show a dramatic decline of 90 members between 1988 and 1989 (Table 1) and a report that renewals were running below 60 percent for the largest category of membership (Table 2). The explanation for the problem that caused the Ad Hoc Membership Committee to be formed in September 1989 may simply be an unusual slowing of renewals or new applications in the first half of 1989.

The conclusion questioning the existence of a growing retention problem does not, however, negate the value of this study of retention. Nor does it preclude the possibility that APLS is facing a crossroads in organizational definition that may have important implications for future growth. Questions meriting further attention will be broached in the discussion that follows the analysis of data about the perceived retention problem.

Plan of Analysis. The first step in the analysis is to discover whether the reported problem of membership retention pertains primarily to members residing outside the U.S. One hypothesis had been that foreign members might be dropping out at a greater rate than U.S. residents, perhaps because they participate in fewer APLS meetings or services.

After narrowing the problem to the population at greatest risk for non-renewal of membership, the analysis will determine whether those who are not political scientists are currently renewing at a lower rate than in the mid-1980s. This question is significant because APLS may be per- ceived to have identified itself more closely with political science when it became a formal section of the American Political Science Association (APSA) in 1986. It is also possible that political scientists might have decided to join the APSA Section and allow their APLS membership to lapse. However, the Ad Hoc Membership Committee learned that most members on the APSA section list appear on the APLS membership list.

The final issue to analyze is the length of membership. Are long-standing members failing to renew or is nonretention confined mainly to individuals who fail to renew after one year of membership? This issue is particularly interesting because the rapid growth from 1985 to 1987 was associated with strenuous efforts funded by the Lilly Endowment to attract new members. Such a growth phase may naturally be followed by attrition that is made more apparent if fewer new members cycle through the organization.

Any valid conclusions about the significance of discipline or length of membership among non-renewals require comparisons. The January 1, 1986 members who did not renew during that year will constitute the baseline for comparison with January 1989 members who did not renew before 1 January 1990. Because the baseline year was just prior to the membership peak, renewals were likely to be as favorable then as in any other year. Limited comparisons will also be made between characteristics of members who failed to renew during 1989 and the total membership residing in the U.S.

Table 3

APLS Members by U.S. and Non-U.S. Residence, 1985 - 1989

\begin{tabular}{lcccc}
\hline Year & $\begin{array}{c}\text { No. Not Residing } \\
\text { in U.S. }\end{array}$ & $\begin{array}{c}\text { Percent of } \\
\text { Personal Membership }\end{array}$ & $\begin{array}{c}\text { No. Residing } \\
\text { in U.S. }\end{array}$ & $\begin{array}{c}\text { Total Personal } \\
\text { Members }\end{array}$ \\
\hline 1985 (mid-year) & 24 & 13 & 159 & 183 \\
1985 (end) & 37 & 17 & 177 & 214 \\
1986 (end) & 36 & 17 & 178 & 214 \\
1987 (end) & 35 & 15 & 196 & 231 \\
1988 (end) & 30 & 15 & 173 & 203 \\
1989 (end) & 28 & 15 & 154 & 182
\end{tabular}

Source: APLS Membership lists dated 1 July 1985 and lists dated January 1 of succeeding years. Membership lists prior to 1985 are unavailable. 


\section{APLS Members Residing Outside the U.S.}

Members residing outside of the U.S. have constituted about 15 percent of the membership over the last five years. Seventy-seven percent of foreign members in January 1988 appear on the 1989 membership list and 87 percent of members in 1989 appear in the January 1990 directory. Although the renewal rate is high, there is no growth in the number of foreign members (Tables 2 and 3). Only 3 new foreign members joined during 1988 (while eight foreign members in January 1988 do not appear on the January 1989 list) and only one or two new foreign members were added by January $1990 .^{1}$

Thus, the analysis clearly demonstrates that the membership residing outside the U.S. is not part of any retention problem. The fact that virtually no growth has been experienced in this segment of the membership in recent years is also notable.

\section{Membership Residing in the U.S.}

In determining membership policies, two questions seem most important:

- Is the interdisciplinary nature of the membership likely to change, due to differences between political scientists and non-political scientists in renewing membership?

- Are new recruits or established members failing to renew their memberships?

These questions will be explored by comparing the U.S.resident APLS members on 1 January 1989 who did not renew with non-renewing members on 1 January 1986 (the 1985 baseline). Comparisons will also be made between non-renewals and the total U.S.-based membership at the end of 1988 on the basis of a 20-percent random sample of U.S.-based members. No distinction between the three categories of personal membership (student, individual and sustaining) can be made.

It must be emphasized that this study is restricted to nonrenewal of personal membership. Before considering comprehensive policy changes, a similar analysis of renewals and of new membership should be undertaken. Detailed knowledge about renewals (the natural complement of this study of non-renewals) and about new members who join the organization is required in order to understand how APLS is changing. Although a 20-percent random sample of the entire year-end U.S. membership provides some basis for understanding the particular characteristics of the non-renewal cohort, time did not allow similar sampling of membership in the baseline year of 1985 .
Discipline/Professional Activity. The small numbers involved suggest that care be taken to guard against overinterpreting the data on Tables 4 and 5. Moreover, the necessity of inferring information about professional activity from mailing addresses makes it impossible to determine whether 50 to 60 percent of non- renewing APLS members in 1985 and 1988 and the overall 1988 membership were political scientists. Academics ${ }^{2}$ who were identified by their addresses as belonging to academic departments that seemed to preclude political science were classified as "not academic political scientists" on Table 4. Therefore, academics of one sort or another appear in all categories; they constituted over 50 percent of the U.S.based membership in 1988.

Although the numbers of non-renewals is small (40 in 1985 and 43 in 1988), Table 4 does suggest that:

- The proportion of non-renewals by academic political scientists identifiable as such fell by half between 1985 and 1988;

- The proportion of non-renewals by academics whose discipline was not ascertainable also declined between 1985 and 1988;

- The proportion of non-renewals by those who are clearly not political scientists, which includes some academics in departments other than political science and many professionals outside of academia, rose between 1985 and 1988;

- The lowest risk of non-renewal was among clearly identified political scientists in 1988;

- The risk of non-renewal may be slightly higher among those who are clearly not political scientists than for the entire 1988 U.S. membership;

- The categories of professional activity or discipline that were not ascertainable failed to renew in roughly the proportion that each constituted in the entire 1988 U.S. membership.

Thus, it appears that political scientists and perhaps academics in general leave APLS at a lower rate now than previously. Perhaps the closer relationship with the American Political Science Association is related to any change in non- renewal patterns. Firm conclusions about the reality of change requires knowledge of such characteristics of the total U.S.- based membership in 1985 as the proportion of identifiable political scientists in that population. 
Table 4

APLS U.S. -Resident Members and Non-Renewals by Discipline/Activity 1985 and 1988

\begin{tabular}{|c|c|c|c|c|c|c|c|}
\hline \multirow[t]{3}{*}{ Discipline/Activity** } & \multicolumn{4}{|c|}{ Year 1988} & \multicolumn{3}{|c|}{ Year 1985} \\
\hline & \multicolumn{2}{|c|}{ Non-Renewals } & \multicolumn{2}{|c|}{$\begin{array}{l}\text { Total U.S.-Resident } \\
\text { Membership* }\end{array}$} & \multicolumn{2}{|c|}{ Non-Renewals } & \multirow{2}{*}{$\begin{array}{c}\begin{array}{c}\text { Total U.S.-Resident } \\
\text { Members }\end{array} \\
\text { No. }\end{array}$} \\
\hline & No. & Percent & No. & Percent & No. & Percent & \\
\hline \multicolumn{8}{|l|}{ Academic Political } \\
\hline Scientist & 3 & 7 & 26 & 15 & 6 & 15 & \\
\hline \multicolumn{8}{|l|}{ Clearly Not Academic } \\
\hline Political Scientist ${ }^{\star \star \star}$ & 18 & 42 & 60 & 35 & 11 & 28 & \\
\hline Not Ascertainable & 22 & 51 & 87 & 51 & 23 & 58 & \\
\hline $\begin{array}{l}\text { Totally Unknown } \\
\text { Academic -- }\end{array}$ & 12 & 28 & 41 & 24 & 7 & 18 & \\
\hline Discipline Unknown & 10 & 23 & 46 & 27 & 16 & 40 & \\
\hline Total & $\underline{43}$ & $\underline{100}$ & $\underline{173}$ & $\underline{100}$ & 40 & $\underline{101}$ & $\underline{177}$ \\
\hline
\end{tabular}

Source: APLS membership lists dated 1 January 1986, 1987, 1989, 1990.

${ }^{*}$ Characteristics of the total U.S.-Resident Membership are based on a randomly-drawn 20-percent sample. Percentages may not add to 100 percent due to rounding.

${ }^{\star \star}$ APLS members who give a university of college political science department as their mailing address are classified as political scientists. Discernably non-academic addresses and academics in other departments constitute the second category. Many members list university or college addresses and are therefore identifiable as academics but give no department identification; they are coded "academic--discipline unknown."

${ }^{\star \star \star}$ Includes academics identified as belonging to a department other than political science.

Membership Longevity. Inquiry into the implications of length of membership for retention is also handicapped by the lack of data. Membership lists for years prior to 1985 are not available. Therefore, it is impossible to study changes in nonrenewals by length of membership.

Table 5 reveals that half of all non-renewals dropped out after two years, although this cohort of lapsed members only constituted a quarter of the total membership on 1 January 1989. These members (who appear on January membership lists in 1988 and 1989) joined during calendar year 1987. First-and third-year members failed to renew in proportions roughly equal to their proportion of the U.S.based membership.
It would be useful to determine whether excessive third year non-renewal is a recurring pattern or whether it is peculiar to the cohort that was recruited in 1987. The year 1987 is notable for two reasons. The Lilly Endowment that supported extensive recruitment activities ended that year. Both mid-year and end-of- year figures show that personal membership reached its peak in 1987. Determining whether the 1987 cohort is peculiar or whether two-year members are in general at highest risk of dropping out requires the replication of this non-renewal study using the January 1988 list and the 1990 list (when the 1991 roster becomes available).

The temptation to explain the high non-renewal rate among two-year members by the size of the 1987 cohort is 
Table 5

1988 APLS U.S-Resident Members and Non-Renewals by Length of Membership

\begin{tabular}{|c|c|c|c|c|}
\hline \multirow[t]{2}{*}{ Years of Membership } & \multicolumn{2}{|c|}{ Non-Renewals } & \multicolumn{2}{|c|}{ Total U.S. Membership* } \\
\hline & No. & Percent & No. & Percent \\
\hline One (1988) & 6 & 14 & 20 & 11 \\
\hline Two & 21 & 49 & 44 & 26 \\
\hline Three & 6 & 14 & 20 & 11 \\
\hline Four or more & 10 & 23 & 89 & 51 \\
\hline Total & $\overline{43^{\star \star}}$ & $\overline{100}$ & $\overline{173}$ & $\overline{99}$ \\
\hline
\end{tabular}

Source: APLS Membership lists dated 1 January 1986, 1987, 1988, 1989, and 1990.

*Characteristics of the total U.S.-Resident membership are based on a randomly-drawn 20-percent sample of the membership list dated January 1, 1989. Percentages may not add to 100 percent due to rounding.

**The first available membership list is dated July 1,1985 . Only 3 of 40 non-renewing members on the January 1, 1986 list do not appear on the mid-year 1985 membership list.

is not valid. Although the organization did have a large number of two-year members in 1988, the membership sample demonstrates that they constituted only a quarter of the total membership. Thus, in 1989 they let their APLS memberships lapse in numbers even more disproportionate than the size of the cohort.

Other important implications of Table 5 suggest that retention is probably not the central problem in maintaining APLS membership levels:

- Over half of APLS membership at the end of 1988 had belonged for four or more years;

- These "old members" constituted non-renewals at a rate equal to about half of their proportion in the entire U.S.based APLS membership in 1988 (i.e., they were less than $25 \%$ of the non-renewals but are $50 \%$ of the organization's membership).

Yet the fact that those leaving the organization in numbers equal to, or greater than their proportion in the entire U.S. membership are disproportionately new members and those who have belonged to APLS for two or three years underlines the Membership Committee's recommendations regarding the need to involve such members in organizational activities or services. Drop-outs among those belonging 1 to 3 years constituted three-quarters of the non-renewals in 1989.

\section{Concluding Discussion}

This study, while limited by the lack of an adequate database on APLS members, does show that the pattern of declining membership is not due to new difficulties in retaining members. Seventy-seven percent of 1985 members renewed during 1986 and 75 percent of 1988 members paid dues during 1989 . The analysis of membership lists shows that by the end of 1989 the perceived crisis which led to the formation of the Ad Hoc Membership Committee had become an overall loss of only $21 \mathrm{mem}$ bers from the previous year and a decline of 49 from the peak achieved in 1987 (Table 3). That high point may have been unsustainable, because it came at the end of aggressive grant-funded recruitment. Yet a loss amounting to 21 percent of the large membership attained by the end of 1987 does require measures to forestall further decline.

Although further research is necessary to make definitive conclusions about the loss of members after two years, this study suggests that the greatest return on efforts to reduce attrition will be produced by targeting secondyear members.

Because overall renewal rates appear to be constant, membership loss must be due to a failure to recruit sufficient numbers of new members to offset predictable non-renewals. Two explanations are possible: 
- APLS is failing to reach potential new members, perhaps because external funds no longer permit aggressive recruitment;

- There are insufficient numbers of potential members, because the "market" for APLS membership is "mature" (i.e., virtually the entire pool of potential members are either current or former members).

Different marketing strategies are appropriate for these quite different situations.

The possibility that the journal editorship and the executive directorship may be divided and the possibility of alliances with other organizations sharing similar interests present possibilities for organizational change. Some of these changes may increase the pool of potential members; others may narrow the appeal of APLS. At issue is the evolution of a living organization, which should be viewed as a stimulating challenge for students of the life sciences.

\section{APPENDIX II \\ Summary of Survey Results of Members Who Dropped, 1988-89³}

1. Why did you join APLS originally?

Subject related to research $4^{4}$

Subject related to teaching 3

Am a political scientist 3

General interest 2

Curious about relationship between socio-behavioral science and political science 1

Recruited by a member 1

Health policy issues 1

Environmental issues 1

Liked looks of mailer 1

2. What were your expectations when you joined APLS?

To get information from journal 3

To see interrelation between engineering and society 1

Thought biomedical field was on cutting edge 1

Bioengineering 1

Environmental issues 1

Social science (not political science) orientation 1

Environmental law 1

Contemporary problems dealing with evolution 1

Political Science in health field 1

Not clear what it was about 1

3. Why did you decide not to renew your membership? Journal did not meet needs 4
Lazy, let it slip 3

Housekeeping 3

Retired 2

Too busy 2

No environmental issues 1

Money 1

Did not receive the journal 1

4. Did you attend APSA meetings? Yes 5; No 7

5. If yes, how many APLS panels did you usually attend? None 2; 1-2 3.

6. Did you ever participate in APLS panels? Yes 1; No 8

7. Did you regularly read PLS? Yes 8; No 5

8. Which items were you likely to read?

Articles 6

Book reviews 5

Bibliographies 3

Commentaries on articles 2

9. Did you find the articles relevant and interesting? Yes 7; No 3

10. Did you find the format (article and responses) useful? Yes 8; No 1

11. What changes, if any, would you like to see in the journal?

More articles 3

Less technical articles-couldn't get a grip on them

Definitive article that invites a forum

Appeal to layman's thoughts; lower level articles; broaden it

Articles need to be more down-to-earth, less academic

More practical application, less scholarly, more interdisciplinary

More implications for sociobiology to contemporary social structures and problems

More on what's happening in science

"Life sciences" does not reflect subject and does not tell much

Present a problem that moves from the individual in its implications to the community

More papers on individual topics

12. Would any of the following have made a difference in your decision not to renew? 
Newsletter? Yes 2; No 7

Annual conference held independently of APSA? Yes 3; No 7

Meetings held abroad? Yes 2; No 8

Greater focus of association? Yes 2; No 7

13. Do you belong to another organization that meets your needs more adequately? Yes 4; No 4

\section{If yes, which?}

American Association for the Advancement of Science; Management Science; Issues in Science; Rural Sociology; Psychological organizations; Science and Technology; Southern Sociological Association; Society for Literature and Science; Society for Social Studies for Science; International Society for Human Ethology

15. Are you a member of APSA (if a Political Scientist)? Yes 3; No 4.

16. What is your primary area of research?

Public law; science and technology; psychology; environmental law. (Note: some were in the private sector - e.g., an attorney for health technology company; a cartoonist; independent consultant; biotechnology sales).

\section{Notes}

1. One established member may have moved from the U.S. to Canada during 1989; thus, only one new member may have been gained. The four foreign members who dropped out during 1989 had all been members for two or more years.

2. Academics are defined as employees of a university or college.

3. This is part of a longer survey. Only questions with several answers are included here.

4. $N=17$. The number at the end indicates the number giving that answer.

\section{MEMORANDUM}

DATE: June 8, 1990

TO: Jim Schubert, Chair, Association for

Politics and The Life Sciences

Tom Wiegele, Editor, Politics and the Life

Sciences

APLS Council

FROM: Roger Masters

RE: Projects to Expand APLS Membership

Three personal additions to the excellent report on APLS membership submitted by Andrea Bonnicksen. Since I was unable to attend the Ad Hoc Committee's "Fly In" meeting, the other members of the Committee deserve all the credit for the work behind her report, which can serve as the basis for concrete initiatives to expand membership.

The report confirms that there is no single explanation for the decision to drop the journal. This makes it reasonable to assume that APLS and the journal are coming close to doing everything feasible to attract members of the "target" audience we have traditionally

defined. This suggests to me several concrete initiatives:

1. Faculty Seminar in Biopolitics. We have often discussed the idea of a Summer Faculty Seminar, which has the advantage of recruiting new interest, suggesting possible courses and research approaches, and therefore broadening the base of those committed to biopolitics. With colleagues in the Gruter Institute, I have begun planning a similar seminar for lawyers interested in biology, which we hope to organize in June 1991. It is conceivable that the Gruter Institute would be willing to co-sponsor a similar seminar with APLS focused on Faculty in political science (or the social sciences more broadly). Such cosponsorship might make it easier to get funding. I would be willing to take the lead on this, but it must be cleared with the Council

from the outset.

2. A Reader in Law, Social Behavior and the State. Closely relate to the Faculty Seminar are plans for a book of readings that could be a basic text in courses. Along with Don Elliott of Yale Law School, Michael McGuire of UCLA, and Alex Capron of the University of Southern California, I am editing such a reader for courses in law schools. Such a book would probably be useful for political scientists as well. A publisher is already interested in the project. 
3. Expansion of the Journal for Politics and the Life Sciences. As the foregoing remarks indicate, there is growing interest in evolutionary biology within each of the social sciences. We need to keep our identity as a group of political scientists who study and teach biopolitics. At the same time, our journal is in financial trouble because there is an insufficiently large base within any one social science discipline for a self-supporting publication. I have long thought that there are two possible solutions we should consider: a cooperative agreement with another professional association with our general orientation that does not have a journal (Evolution and Human Behavior Society, International Society for Human Ethology, Gruter Institute for Law and Behavioral Research); a cooperative merger with another journal which, like ours, has a subscription that is below the self-sustaining level.

1) Cooperative Agreement. Other groups like the Evolution and Human Behavior Society, the Gruter Institute for Law and Behavioral Research, and The International Society for Human Ethology have membership lists cutting across disciplines. We would at least double the distribution of the journal by a cooperative agreement with any one of these groups. For some, an agreement might best be one in which each organization had control over a separate section of the journal - i.e., it could have "Departments" for articles targeted to its primary audience. Much, of course, would be common - general interest articles, book reviews, etc. An expansion of the length of each issue would be necessary, but could make the journal self-sustaining.

2) Cooperative Merger. Several journals now exist that may be interested in a merger. Combination with another journal, like a cooperative agreement between associations, would expand the journal's subscription toward a self-sustaining level while permitting the Association to retain its identity. I know one University Press whose willingness to take over publication of PLS depends on an expansion of this sort.

\section{Actions to Be Taken}

It seems to me that the Association needs to explore options in a flexible way. With regard to a Faculty Seminar in Biopolitics, I would be willing to pursue negotiations with the Gruter Institute to see if a proposal can be made to the Council at a meeting in San Francisco - with the full understanding that APLS is in no way engaged by my so doing. Is this acceptable? On the Journal, I think we need to delegate authority to a small committee (Tom, Odelia and Jim) to propose options.

\section{OTHER NEWS}

\section{European Sociobiological Society}

The 13th meeting of the European Sociobiological Society (ESS) was held at the Department of Political Science and International Affairs, University of Tampere, Finland, August 10-12, 1990. The theme of the meeting was "Fifteen Years of Sociobiology: Retrospect and Prospects." However, this theme attracted only eight papergivers to Tampere, and only a few of the papers directly concerned the general theme of the convention. The meeting of the Human Behavior and Evolution Society, held only a week later in Los Angeles, probably decreased participation from Western Europe. In fact, most of the papergivers were from Eastern Europe and India, and this indicates the spread of sociobiological ideas to the East.

The following papers were presented at the ESS meeting in Tampere: Tatiana Chernigovskaya, Sechenov Institute of Evolutionary Psychology, USSR Academy of Sciences, Leningrad: "Neuropsychological and Cross-Cultural Approaches to Cognitive Processes;" Vitaliy Egorov, Department of Psychiatry, Crimean Medical Institute, Simferopol, U.S.S.R.: "Sociobiology and Psychiatry: Toward a New Synthesis;" Valentina Leonovicova, Laboratory of Evolutionary Biology of the Czechoslovak Academy of Sciences, Prague: "Sociobiology in Eastern Europe: Retrospective and Prospects;" R. Srinivasa Rao, Department of Education, Sri Venkateswara University, Tirupati, Andhra Pradesh, India: "The Positive Influence of Sociobiology on Human Development;" Pouwel Slurink, Faculty of Philosophy, Catholic University, Nijmegen, the Netherlands: "Sociobiology and the Perennial Problems of Philosophy;" A. Srivastava, Department of Zoology, University of Jodhpur, India: "Infanticidal Efforts by a Subadult Male Langur: a Fact Sociobiology Fails to Explain;” Tatu Vanhanen, Department of Political Science and International Affairs, University of Tampere, Finland: "Thirteen Years of Sociobiology in Finland;" and Jan Wind, Institute of Human Genetics, Free University, Amsterdam: "Some Sociobiological Reflections on the Sexual Dimorphisms of the Human Larynx."

From the perspective of political science, Pouwel Slurink's talk on his doctoral thesis concerning sociobiology and the perennial problems of philosophy was probably the most interesting. He argued that philosophy, as the perennial quest for truth about the human situation and about human destiny, has much to learn from sociobiology. He tried to

cc: Ad Hoc Committee 